\title{
FLOW ANALISYS FOR A DOUBLE SUCTION CENTRIFUGAL MACHINE IN THE PUMP AND TURBINE OPERATION MODES
}

González, José; Fernández Oro, Jesús Manuel; Argüelles, Katia Ma; Santolaria, Carlos. Universidad de Oviedo, Área de Mecánica de Fluidos. Campus de Viesques, 33271 Gijón (Asturias), Spain. aviados@uniovi.es

\begin{abstract}
A double suction centrifugal machine has been studied, both experimentally and numerically, working as a pump and as a turbine. Experimentally, the static performance of the machine working as a pump was obtained. These measurements were compared with equivalent numerical results from a URANS calculation. As a second step, the numerical results have been exploited to get detailed information about the flow in both operating modes (pump and turbine).
\end{abstract}

The main goal of the study is, in one hand, the validation of the numerical procedure proposed and, in the other hand, the possible turbine operation of the impeller, which could point out a wider working range for the machine. The first is handled by detailed analysis in the pump mode, according to previous experience of the research group. The second is aimed by using the numerical model and explore the flow fields obtained, when working in such inverse mode. Therefore, the presented results germane the numerical method with the not so common turbine mode of operation, providing insight into the flow characteristics.

When working as a pump, the flow at the suction is characterized by the existence of an inlet tongue, which intends to enforce a uniform flow for nominal flow rate. For the turbine 


\begin{abstract}
mode; flow patterns in the impeller, volute and suction regions are carefully investigated. The influence of the specific geometrical arrangement is also considered for this operation mode. Therefore, the study considers, the particular numerical values are considered and deeply analysed.
\end{abstract}




\section{INTRODUCTION}

The global complexity of any study of the flow in a centrifugal impeller has promoted the development of many studies (among others, Karassik et al. [1], Neumann [2]). If the geometry of the volute casing has any particularities like a double suction at the inlet or a double volute tongue at the outlet, the flow structure becomes even more complex and is still far from being fully understood (Neumann [2]).

The flow in any hydraulic turbomachine is always 3D and unsteady. Therefore, any analysis should be done keeping both the dynamic and 3D effects. Actually, the combination of both gives rise to the real working flow patterns (Neumann [2]). Although, even today, the design of any of those machines starts with a steady flow assumption, this approach is only valid for operating points near the design or nominal one. Therefore, more complex and accurate data are needed.

Being the considered geometry in the present study, a double suction pump is a quite common solution when cavitation problems are likely to arise (Kyung et al. [3]). They are usually suitable in applications where a high flow rate is needed and in situations where the axial forces could establish a limitation for a conventional model. The axial balance and the possibility of increasing the flow rate might, as a drawback, increase the radial forces. As in any pump, the fluid flow is inherently unsteady, being this the most important source of vibration and hydraulic noise (Brennen [4]). 
Different numerical methods to treat the URANS equations for turbomachinery applications have been widely developed. This particular field is just an example of the many applications where the numerical solution of the flow has proven its worth (Gunzburger et al. [5]). Although predictions on the flow field are always valuable, the numerical simulation of a commercial pump is not easy due to the usual CFD difficulties: turbulence modelling, flow separation, boundary layer, etc (Laskminarayana [6]). For the case studied here, there are also some particular problems like the extremely difficult geometry (especially at the inlet) and the complex flow dynamic effects. Some clear examples of numerical solution applied to the dynamic effects on centrifugal pumps have been reported in different references (Shi et al. [7], Tsukamoto et al. [8], Croba et al. [9] and González et al. [10]).

The experimental facilities and apparatus to perform a detailed and dynamic flow analysis inside any hydraulic machine have become more and more complex and expensive. It is in this frame where the CFD techniques find their direct application. With the updated numerical techniques almost any geometry can be analysed and meaningful information can be obtained (Lakshminarayana [6]). In this frame, the numerical research on hydraulic machinery has been increasingly used as a design tool, particularly in the field of the centrifugal machines (González et al. [10]).

In this paper, a numerical model for the analysis of the flow inside a double suction machine is presented and pressure or velocity fields at different locations are analyzed. These numerical simulations, performed for different operating conditions and for the two modes 
(pump and turbine), were carefully analyzed and valuable conclusions in what refers to the flow structure will be reported along the paper.

The use of pump impellers as turbines is not new and many efforts have been directed towards the application of such arrangements (Kittredge, [11]). Since the beginning of such applications until the modern pump-turbines (so widely designed), many improvements and cost effectiveness studies have been carried out. Mainly used for small powers, many authors have pointed out the advantageous use of centrifugal impellers working as turbines (Fernández et al., [12], among others). Nevertheless, the use of a double suction geometry to work in the turbine mode could be seen as a source of problems, due to the specific arrangement of this kind of designs. Therefore, a need for a better understanding of the flow behaviour inside a double suction machine working in the turbine mode is needed.

Actually, the combination of both a double suction geometry and a numerical study has become the subject of some recent works (Kyung, C. et al., [3] and González et al., [10]). In this paper, a research into the possible application of a double suction pump working as a turbine is presented.

Once the model was validated through performance curve comparison, the flow patterns in the impeller, volute and suction regions have been investigated. Particularly, the suction flow field is of special interest due to induced modification of the axial and circumferential velocity 
fields. Besides that, the pressure evolution is also considered in order to study the different patterns at the inlet of the pump, where cavitation is likely to arise.

In general, the CFD techniques provide a good approach for predicting general trends in possible new designs or extending them to different operation modes in existing machines. This latter being the point considered in the present study, indicating a possible working range for the existing pump when operating as a turbine, with optimum efficiency levels. From this study, an optimisation of the geometry could also be performed, although this would depend on future requirements and perspectives.

\section{MACHINE DESCRIPTION AND EXPERIMENTAL TESTS}

A six blade double aspirating impeller (Fig. 1) with a maximum diameter of $0.46 \mathrm{~m}$ and a blade angle of $32^{\circ}$ at that position is considered for the study. The volute casing (Fig. 2) and pipes present a typical configuration for this kind of machines (see González et al., [13]). A vaneless configuration is available, although an inlet tongue is manufactured. This inlet tongue, designed for the pumping mode, becomes an outlet obstacle, when working as a turbine.

In the hydraulic setup used for the experiments, water was pumped from and returned to a $200 \mathrm{~m}^{3}$ reservoir. The tested pump had a single double suction duct and a vaneless spiral volute casing. The main parameters of this pump are presented in Table 1. The rotational speed was set to $\omega= \pm 154.99 \mathrm{rad} / \mathrm{s}$, being the positive value for the pump mode and the negative for the turbine one. 
Standard pressure manometers were used for the head measurements. To obtain the flow rate, an electromagnetic Krohne flow-meter was installed. Flow rate uncertainties were found to be always less than \pm 2.5 percent (confidence level of 95 percent). The head and efficiency uncertainties were kept under \pm 1.5 percent for the pump mode, within the same confidence level. All uncertainty analysis were carried out following the procedures proposed in Kline [14].

For the turbine mode, no experimental results were available. The goal of the study, for such operating mode would be the finding of the machine possibilities to work with efficiency and reliability enough.

The relative high specific speed and the double suction at the inlet are the relevant features of the studied pump. A definition of the flow features can be obtained if the numerical model is considered (Fig. 3). The reference planes shown in this Fig. 3 will be used in the following stages of the study. The symmetry plane $(Z=0)$ sets the reference for different planes in which the increasing $\mathrm{Z}$ (values higher than $\mathrm{Z}=0.15$ ) means a section placed more upstream of the rotor inlet.

\section{NUMERICAL MODEL}

The 3D unsteady Navier-Stokes equations were solved using the FLUENT sotware. Due to symmetry considerations, only half of the pump was modelled. 


\section{Geometry and grid}

The discretization of the geometry was done keeping the balance between calculation time (details included in section numerical solution control) and the accuracy order of the simulation for the flow structure. In any case, the average CPU time was kept on the order of 350 hours. Special care was observed in the region near the tongue by carrying a detailed study of flow vectors and stagnation point placement. Unstructured mesh of tetrahedral cells was generated to define the inlet and outlet zones (more than 100000 cells and around 150000 cells, respectively) and the same kind of cells were used to define the impeller and volute (almost 250000 cells and 235000 cells, respectively). In the volute, a mesh refined zone was defined for the region close to the tongue. The particular features of the mesh were also compared with previous experience of the group (for example, see González et al. [10]) and found to be appropriate. Some global tests (with the whole machine) also indicated that cell number was reasonably in the required range.

Once the geometry was defined, the model was ready to be simulated. The final grid generated for the inlet section, the volute and the impeller are shown in Fig. 4. The sliding mesh technique has been widely used in the last decades by turbomachinery researchers (for instance and for a centrifugal pump application, see Croba et al. [9]). It basically consist of a numerical procedure that allows a proper variable transfer from a moving mesh into an static one. Therefore, it becomes very straightforward its use in a turbomachine, where the impeller rotates and there are also static parts. Obviously, this features are also to be considerer here. Two different meshes are then considered, one rotating with the impeller, while the other remains 
static (inlet and outlet pipes and the two volutes). Consequently, two sliding zones must be defined to allow the relative motion of the meshes in both inlet and outlet sections.

\section{Mathematical model}

The numerical code used (FLUENT) solves the fully 3D incompressible Navier-Stokes equations, including the centrifugal force source in the impeller and the unsteady terms. Turbulence was simulated with the standard k- $\varepsilon$ model. Although grid size was not adequate to investigate the local boundary layer variables, global values were well captured and the details of the flow near the tongue seems to follow the usual trends found in the bibliography (Brennen [4]). For the flow calculations, wall functions based on the logarithmic law, were used. The time dependent term was discretized with a second order implicit scheme. The pressure-velocity coupling was calculated through the SIMPLEC algorithm. Second order, upwind discretizations were used for convection terms and central difference schemes for diffusion terms. This procedure has been widely used with big success for other geometries (Gonzalez et al. [10]).

\section{Boundary conditions}

The modelled boundary conditions were the ones considered with more physical meaning for turbomachinery flow simulations. For the pump operating mode, those were total pressure equal to zero at the inlet and a pressure drop proportional to the kinetic energy at the outlet. The flow rate was changed by modifying the constant for that pressure drop at the outlet condition, which simulates the closure of a valve. Again, the no-slip condition with a logarithmic law for the boundary layers was imposed over the impeller blades and walls, the volute casing and the inlet pipe wall. Using this boundary conditions, comparison between different operating points can 
give rise to possible cavitation inception detection (same pressure level at the inlet), although this is not the goal in this research.

For the turbine operating mode, static pressure was set equal to zero at the exit and a total pressure was imposed at the inlet. The flow rate was changed by modifying that total pressure at the inlet. Again, the no-slip condition with a logarithmic law for the boundary layers was imposed over the impeller blades and walls, the volute casing and the inlet pipe wall. Using these boundary conditions, comparison between different operating conditions becomes straightforward.

The boundary conditions for the turbulent model are fixed at the inlet of each domain, which changes depending on the operation mode. The k- $\varepsilon$ clousure model works with the input of the inlet turbulence level, in percentage of the inlet velocity. From that, it obtains the kinetic turbulence energy $(\mathrm{k})$ and with the inlet diameter, it internally calculates the derived turbulent variables ( $\varepsilon$ and the eddy viscosity).

\section{Numerical solution control}

A cluster with twenty Athlon-K7 nodes was used for the calculations. The time step used in the unsteady calculation was set to 0.0002703 seconds in order to get enough time resolution for the dynamic analysis (Courant number was kept below 3, which assures very good time accuracy and numerical stability). Mesh independency was studied only through local refinement near the volute tongue. Some preliminary test with lower number of cells indicated neither local or global flow variations. This approach is selected due to the obvious numerical restriction in 
terms of CPU time. Although it can be observed as a weakness of the model, the bigger cell size is in the range considered as optimum for other centrifugal pump geometries, previously studied by the authors (Gonzalez [16] and González et al. [10]).

The number of iterations was adjusted to reduce the residual below an acceptable value in each time step. In particular, the ratio between the sum of the residuals and the sum of the fluxes for a given variable in all the cells was reduced to the value of $10^{-5}$ (five orders of magnitude). Initialising the unsteady calculation with the steady solution, over 10 impeller revolutions were needed to achieve the periodic unsteady solution convergence. Such calculations correspond to an average CPU time of 350 hours.

The numerical accuracy of both steady results (either for the pump or turbine operation modes) was estimated to be on the order of $2 \%$ and $1 \%$, respectively. During the numerical study, the guidelines proposed in [17] were used and the numerical uncertainty was related to the change in certain reference values when different mesh refinements were considered. Therefore, the values obtained for accuracy can be considered reasonable enough as to validate the numerical results.

\section{STATIC RESULTS AND DISCUSSION FOR BOTH OPERATION MODES}

After the periodic state was obtained, the unsteady results were averaged over a blade passing interval. The first comparison is made for the performance curves working as a pump 
and shown in Fig. 5. For these performance curves, the axis are made non-dimensional using the relationships:

$$
\begin{gathered}
\phi=\frac{\mathrm{Q}}{\pi \mathrm{D}_{2} \mathrm{~b}_{2} \mathrm{U}_{2}} \\
\psi=\frac{\mathrm{g} \mathrm{H}}{\mathrm{U}_{2}^{2} / 2}
\end{gathered}
$$

Where the subscript 2 refers to the outlet section for the pump mode, which corresponds to the inlet when the machine is working as a turbine. As can be observed for the head curve, the prediction of separation at low flow rates is not fully accomplished with the numerical solution and some differences are found at the lower flow rates. However, at nominal and higher flow rates, both the numerical and the experimental curve are almost one on top of the other. So, for the general comparison, the agreement found between both curves has encouraged the research and detailed flow analysis has been performed, and will be explained in what follows.

Nominal flow rate is numerically predicted at $\phi=0.30$, slightly lower than experimentally $(\phi=0.32)$. Therefore, the agreement for the determination of this nominal flow rate is considered very good. 
For the efficiency curves, more differences are found. An explanation for such differences comes from the fact that the torque for the experimental efficiency calculation was measured in the shaft, while the numerical torque does not considered the mechanical losses and the disk friction at the impeller hub and shroud.

Considering the turbine mode no comparison with experimental results are possible and the numerical study of the same impeller geometry was carried out to analyse the possibilities of such geometry working as a turbine. With the proposed boundary conditions, a full evolution of the performance curve was obtained. For such purpose, torque and required head as a function of the flow rate are plotted in Fig. 6. This performance curves were obtained for the same rotational speed as the pump, but with opposite direction, that is, $\omega=-154.99 \mathrm{rad} / \mathrm{s}$.

As can be seen in Fig. 6, typical behaviour of performance curves are found for the studied impeller working as a turbine. Particularly, an almost constant efficiency of $80 \%$ for flow rates varying in the range $\phi=0.3$ to 0.4 followed by a quick fall for lower flow rates were numerically obtained. The required total head at the inlet also follows typical turbine trends.

The shape of the curves agree with the expected trend for a centrifugal turbine (Kittredge, [11]). The best efficiency point flow rate is relatively similar to the equivalent one for the pump mode. Accepting these numerical results, a detailed flow analysis was also carried out for the 
turbine mode, with the aim of finding the most relevant flow occurrences if the operation of the machine as a turbine were to be finally put into practise.

\section{DETAILED FLOW ANALYSIS FOR THE PUMP MODE}

The averaged unsteady fields were obtained for different flow rates in order to analyse the different working conditions inside the pump. With this goal in mind, the pressure and velocity for different positions of the impeller were numerically obtained. An example of the static pressure values for the symmetry plane is shown in Fig. 7. In this case, the nominal flow rate is considered and, therefore a quite axi-symmetric pattern for the pressure distribution in the impeller is obtained.

From now on, the blade passing average values are presented in order to explain the global behaviours and the model feasibility to describe the particular flow features. Previous studies for a single suction centrifugal pump (Parrondo et al. [18]) have pointed out the relevancy of the detailed flow analysis, as it will performed here.

The study of the flow conditions at different sections is firstly focused on the calculated structure around the volute. For a low flow rate (see Fig.8 for $\phi=0.13$ ) an important acceleration together with important low speed region is observed near the tongue. The separation point is placed somewhere downstream of the volute tongue in the discharge direction, which agrees with the expected trend for a centrifugal pump (see Miner et al., [15]). 
For the nominal flow rate (as can be seen in Fig. 9) a better flow distribution around the tongue was obtained. Therefore, minimum loss condition is attained for flow rates close to the one in this figure, $\phi=0.30$. At this operating point, the tongue softly divides the flow into two parts.

On the other hand, for flow rates higher than the nominal one (Fig. 10 for $\phi=0.36$ ), a strong re-circulation bubble is found downstream of the tongue in the volute direction. Again, the losses are increased and the relative position of the separation point agrees with the expected trend for low flow rates.

The effect of the inlet geometry is then considered. For this purpose, pressure at two sections is averaged and presented here. The two sections are $\mathrm{Z}=0.250 \mathrm{~m}$ (side inlet of the pump) and $\mathrm{Z}=0.15 \mathrm{~m}$ (just before the impeller). For both sections and three different flow rates (nominal one, low and high) the pressure is considered. The same colour scale is maintained to allow a direct comparison of the results.

In the first section $(Z=0.250 \mathrm{~m})$, the geometry of the pump introduces a semi-volute at the inlet suction, aiming a uniform flow conditions (at least for nominal flow rates, Neumann [2]). The effect of this second geometrical constraint is superimposed to the tongue effect (in the discharge volute) and shortens the range of flow rate with reasonable good efficiency (Fig. 7). 
Three different flow rates are analysed using a $45000 \mathrm{~Pa}$ scale (from $-40000 \mathrm{~Pa}$ to 5000 $\mathrm{Pa}$ ) for the averaged pressure field and the numerical results are shown in Figs. 11 to 13. One must keep in mind that the total pressure at the inlet is always set to zero. The flow in the pump mode evolves in a direction normal to the drawing plane and then around the central orifice. If the case of a good inlet duct design, it would impose a uniform inlet condition. Fig. 12 shows the pressure field for the nominal flow rate and (as can be observed) it does produce a quite uniform inlet condition. For the other figures showing the pressure distributions (Figs. 11 and 13), the pressure patterns look similar, although the pressure changes more in Fig. 13 due to the higher velocity.

No reverse flow from the impeller is observed when the velocity fields are analysed, even at low flow rate $(\phi=0.13)$,. Nevertheless, the effect of the flow deceleration on the concave hub side at the inlet is found and plotted in a plane normal to $\mathrm{Z}$ axis (see Fig. 14).

Therefore, considering these pressure distribution figures, the conclusion to be drawn is that the semi volute at the suction inlet works quite well making a uniform inlet for nominal flow rate. The numerical results point out a better uniformity for low flow rates in sections upstream of the impeller, but when approaching the impeller, the uniform inlet is obtained for flow rates close to the nominal one.

Some possible cavitation problems are likely to be found. Static pressure of $-100000 \mathrm{~Pa}$, relative to the $0 \mathrm{~Pa}$ imposed as total pressure at the domain inlet were found for the highest flow 
rate in a very narrow zone, at the impeller inlet. The effect of these possible problems should be taken into account as far as the operation of the studied machine would be of interest for such flow rates. However, this is not the main goal of the present article.

As previously mentioned, the dynamic effects (studied for a single suction centrifugal pump in Parrondo et al. [18] for a simple aspiration centrifugal pump) have not been analysed in this paper, due to the lack of experimental measurements to compare. However, the unsteady model developed here can be focused on this direction in the near future.

\section{DETAILED FLOW ANALYSIS FOR THE TURBINE MODE}

Due to unsteady procedure used during the calculation, an averaging method had to be introduced in order to analyse the flow field. The average passage flow was considered. Two different sets of figures are discussed here, containing the pressure and velocity averaged values for a blade passing period. Two different sections or flow regions have been considered and will be shown. Firstly, the semi-volute section (same section as shown in Figs. 11 to 13) is presented and, secondly a flow analysis in the impeller is intended.

In Fig. 15, the absolute velocity field at the exit casing with the presence of the semivolute tongue is plotted for three different flow rates. In particular, $\phi=0.23$ or low flow rate is plotted in the upper left side of the figure, $\phi=0.32$ or nominal flow rate is plotted in the upper right side and $\phi=0.42$ or high flow rate is plotted in the lower part of the figure. The same scale velocity range is considered for the three figures $(0-11 \mathrm{~m} / \mathrm{s})$ and they are grouped to better 
understand the comparisons. As stated before, the semi-volute tongue is introduced looking for uniform flow conditions. These conditions are not so important in the turbine mode of operation, as far as the semi-volute tongue is now at the flow outlet.

Nevertheless, and for the nominal and lower flow rates quite uniform velocity contours are clearly obtained. One must consider that for such range of low rates lower velocities are found and the velocity gradients become less important. At high flow rates (lower part of the Fig. 15) the velocity range increases. Somehow, the outlet condition is still uniform, as observed in the near impeller exit zone. Obviously, the velocity there has also increased in comparison with the previously analyzed flows, but the average value at that exit zone is kept reasonably constant. But, contrarily to the lower flow rates, a big area with a strong velocity gradient is found downstream. This is visible at the right side of this high flow rate figure: a region with almost 0 velocity is very near another region with a velocity around $7.0 \mathrm{~m} / \mathrm{s}$. As a straightforward effect, lack of axy-symmetry is produced and more losses are created. The, the use of the machine on this flow rates should be limited to short operations time, but never considered as a permanent working condition.

Secondly, the averaged pressure field in the impeller is plotted in Fig. 16. The same three flow rates considered in Fig. 15 are now studied, but for the relative flow conditions. Again, a standard pressure range is considered to let comparisons be easier. In particular, a range from 100000 to $+800000 \mathrm{~Pa}$ scale is used for the three flow rates. The three fields correspond to $\phi=$ 0.23 , at the left side of the figure. Then $\phi=0.32$, or nominal flow rate, plotted in the centre of the 
figure. And, finally $\phi=0.42$, placed at the right hand side of the figure. The area plotted in this Fig. 16 corresponds to the hub of the turbine from the inlet (without the casing) and the curved surface is, therefore, observed as the inlet circle (without the outlet section, in the middle).

Very constant pressure field is recovered for the nominal flow rate (centre of the figure) for a given radial positions (any circle considered in the figure). That is, a very uniform pressure decrease is found from inlet to outlet of the impeller.

For both low and high flow rates (placed respectively at the left and right hand side of the figure) stronger effect of the blades is observed. Particularly, for the higher flow rate (right hand side figure), a quite important lack of axy-symmetry is found.

So, as expected, a stronger flow periodicity can be observed (softer and more periodic pressure decrease from the inlet to the outlet section) if one compares the central figure with the ones at its sides. Also, considering the previously shown velocity field, a lower change in the flow direction is recovered relatively to the blade angle for the nominal flow rate.

Figs. 15 and 16 show the maximum and minimum studied flow rates for the turbine operation mode. However, there have been some intermediate flow rates numerically analysed, but those flow rates do no present any contradictory results and, therefore, conclusions have been grouped into low, nominal and high flow rates. On the other hand, higher or lower flow rates, in comparison with the studied ones, would be of no practical interest for the considered geometry. 
The observed flow patterns for the turbine mode of operation stress the fact that the proposed geometry would perform quite well for the nominal and lower flow rates. The modelled fields do point to worse operation for high flow rates. If this machine is to be placed in a reversing operation hydraulic plant, this limitation would not be a problem as this kind of installations do need a high flow rate operating regime basically for the pumping mode.

\section{CONCLUSIONS}

An analysis of the flow inside a double aspirating centrifugal machine has been carried out. The study is performed using a CFD technique based on the sliding mesh and the real movement of the impeller. Comparisons with experimental data are available for the pump operation mode.

For the pump mode, design and off-design values have been recorded and a very good agreement has been found for the performance curve experimentally measured. The separation zones in the nearby of the volute tongue have been numerically observed and do agree with the expected trends, according to the bibliography.

One particular feature found for the studied pump mode is the lack of uniform inlet except for flow rates near the nominal one. It seems that the pump geometry produces a deviation from the axi-symmetric flow distributions even for small differences (above and 


\begin{abstract}
bellow) from the nominal flow rates. This might lead to important radial forces, that could limit the use of this particular design.
\end{abstract}

In spite of the difficulties induced by the geometrical complexity at the exit of the machine when working as a turbine, due to the double arrangement with a flow splitting effect, relative high efficiencies were numerically obtained for the impeller under consideration (values up to $80 \%$ ). As in any turbine, the regulation and piping systems should be carefully designed to avoid possible unsteady phenomena.

Working as a turbine, and from the detailed flow analysis, a confirmation of the general and global trends observed on the performance curve is made possible. The higher flow rate studied give rise to important lack of uniform conditions for the flow inside and after the impeller. Therefore, the optimum working range for this impeller in a turbine mode is quite more limited than the expected one from the performance curve, and would not be in this high flow rates range.

Therefore, the cost effectiveness and proper working variables have been numerically obtained for the studied geometry. Some complementary experimental results for the turbine mode of operation and for the dynamic flow structure would be of big interest if a full validation of the numerical data obtained was aimed. Despite this lack of experimental data, the numerical results do improve the knowledge of the flow features inside a so complex machine and, basically point out to a good performance in both operation modes. 


\section{ACKNOWLEDGMENTS}

The authors acknowledge the financial support from the Ministerio de Ciencia y Tecnología (Spain) under projects MCT-01-DPI-2598, DPI2002-04266-C02-02 and DPI-2006-15638-C0201.

\section{NOMENCLATURE}

$\mathrm{D}_{2} \quad$ Impeller diameter at outlet, [m].

$\mathrm{H}, \mathrm{H}_{\mathrm{N}} \quad$ Pump head and pump head at the best efficiency point (nominal), [m].

$\mathrm{k} \quad$ Turbulent kinetic energy, $\left[\mathrm{m}^{2} / \mathrm{s}^{2}\right]$.

$\mathrm{Q}, \mathrm{Q}_{\mathrm{N}} \quad$ Flow rate and flow rate at nominal point, $\left[\mathrm{m}^{3} / \mathrm{s}\right]$.

$\mathrm{t}$ Time, [s].

$\mathrm{U}_{2} \quad$ Peripheral velocity at impeller outlet, [m/s].

$\mathrm{X}, \mathrm{Y}, \mathrm{Z} \quad$ Coordinate system, [m].

$\mathrm{Z} \quad$ Number of blades, [-].

$\beta_{2} \quad$ Impeller blade angle (outlet section), [deg].

$\varepsilon \quad$ Turbulent dissipation, $\left[\mathrm{m}^{2} / \mathrm{s}^{3}\right]$.

$\phi \quad$ Flow coefficient, see equation (1), [-].

$\rho \quad$ Density of the fluid (water in this paper), $\left[\mathrm{Kg} / \mathrm{m}^{3}\right]$.

$\omega, \omega_{\mathrm{S}} \quad$ Rotating speed and specific speed, respectively, where $\omega_{\mathrm{S}}=\omega_{\mathrm{N}}{ }^{1 / 2} /\left(\mathrm{gH} \mathrm{H}_{\mathrm{N}}\right)^{3 / 4},[\mathrm{rd} / \mathrm{s}]$ and [-].

$\psi \quad$ Head coefficient according to equation (2), [-].

$\eta \quad$ Machine efficiency, [-].

\section{REFERENCES}

[1] Karassik, IG, Krutzsch, WC, Fraser, WH, Messina, JP. Pump Handbook, Mc. Graw Hill, 1985, 2nd edition. 
[2] Neumann, B. The Interaction between Geometry and Performance of a Centrifugal Pump, MEP: London, 1991.

[3] Kyung, C, Pyun, P, Hyun, C, Sang, L. A study of flow analysis for a double suction centrifugal pump. FEDSM2002-31180, 2002.

[4] Brennen, CE. Hydrodynamics of Pumps. Oxford University Press and CETI Inc,1994.

[5] Gunzburger, MD, Nicolaides, RA. Incompressible Computational Fluid Dynamics. Trends and Advances. Cambridge University Press, 1993.

[6] Laskminarayana, B. Fluid Dynamics and Heat Transfer of Turbomachinery. Wiley Interscience, 1996.

[7] Shi, F, Tsukamoto, H. Numerical study of pressure fluctuations caused by impeller-diffuser interaction in a diffuser pump stage. Journal of Fluids Engineering 2001; 123: 466-474.

[8] Tsukamoto, H, Uno, M, Hamafuku, N, Okamura, T. Pressure fluctuation downstream of a diffuser pump impeller. ASME FED (Unsteady flows) 1995; 216:133-138. 
[9] Croba, D, Kueny, JL. Numerical Calculation of 2D, Unsteady flow in centrifugal pumps: impeller and volute interaction. Inernational Journal for Numerical Methods in Fluids 1996; 22: 467-481.

[10] González, J, Fernández, J, Blanco, E, Santolaria, C. Numerical simulation of the dynamic effects due to impeller-volute interaction in a centrifugal pump. Journal of Fluids Engineering 2002; 124: 348-55, DOI: 10.1115/1.2173294.

[11] Kittredge, CP. Centrifugal pumps used as hydraulic turbines. Transactions of the ASME $1941 ; 63$.

[12] Fernández, J, Santolaria, C, Ballesteros, R, Blanco, E. Test facility of inverse-working pumps for small and very small hydro-power plants. Procs. of the International Congress on Hydropower into the next Century 1995; 1: 657-664.

[13] González, J, Santolaria, C, Castro, F, Parra, MT. Numerical model for the unsteady flow behaviour inside a double suction pump. FEDSM2003-45396 2003; 2B:1149-1155.

[14] Kline, SJ. The Purposes of Uncertainty Analysis. Journal of Fluids Engineering 1985; 107: $153-160$.

[15] Miner, SM, Flack, RD, Allaire, PE. Two dimensional flow analysis of a laboratory centrifugal pump. Journal of Fluids Engineering 1992; 114: 333-339. 
[16] González, J. Modelización Numérica del Flujo no Estacionario en Bombas Centrífugas. Efectos Dinámicos de la Interacción entre Rodete y Voluta. Ph.D. Thesis (in Spanish), Universidad de Oviedo, Spain, 2000.

[17] Freitas, CJ. Journal of fluids engineering editorial policy statement on the control of numerical accuracy. Journal of Fluids Engineering 1993; 115: 339-340.

[18] Parrondo, JL., González, J, Fernández, J. The effect of the operating point on the pressure fluctuations at the blade passage frequency in the volute of a centrifugal pump. Journal of Fluids Engineering 2002; 124: 401-410, DOI: 10.1115/1.1493814. 


\begin{tabular}{|c|c|}
\hline Number of blades: & $z=6$ \\
\hline Impeller outlet diameter: & $\mathrm{D}_{2}=0.46 \mathrm{~m}$ \\
\hline Outlet blade angle: & $\beta_{2}=32 \mathrm{deg}$ \\
\hline Rotational speed: & $\omega=+/-154.99 \mathrm{rd} / \mathrm{s}$ \\
\hline Nominal flow rate (Pump mode): & $\mathrm{Q}_{\mathrm{N}}=0.694 \mathrm{~m}^{3} / \mathrm{s}$ \\
\hline Head at nominal flow rate (Pump mode): & $\mathrm{H}_{\mathrm{N}}=49.50 \mathrm{~m}$ \\
\hline Specific speed (Pump mode): & $\omega_{\mathrm{S}}=1.25$ \\
\hline Nominal flow rate (Turbine mode): & $\mathrm{Q}_{\mathrm{N}}=0.708 \mathrm{~m}^{3} / \mathrm{s}$ \\
\hline Head at nominal flow rate (Turbine mode): & $\mathrm{H}_{\mathrm{N}}=59.80 \mathrm{~m}$ \\
\hline Specific speed (Turbine mode): & $\omega_{\mathrm{S}}=1.13$ \\
\hline
\end{tabular}

Table 1.- Machine main dimensions and nominal operating points. 


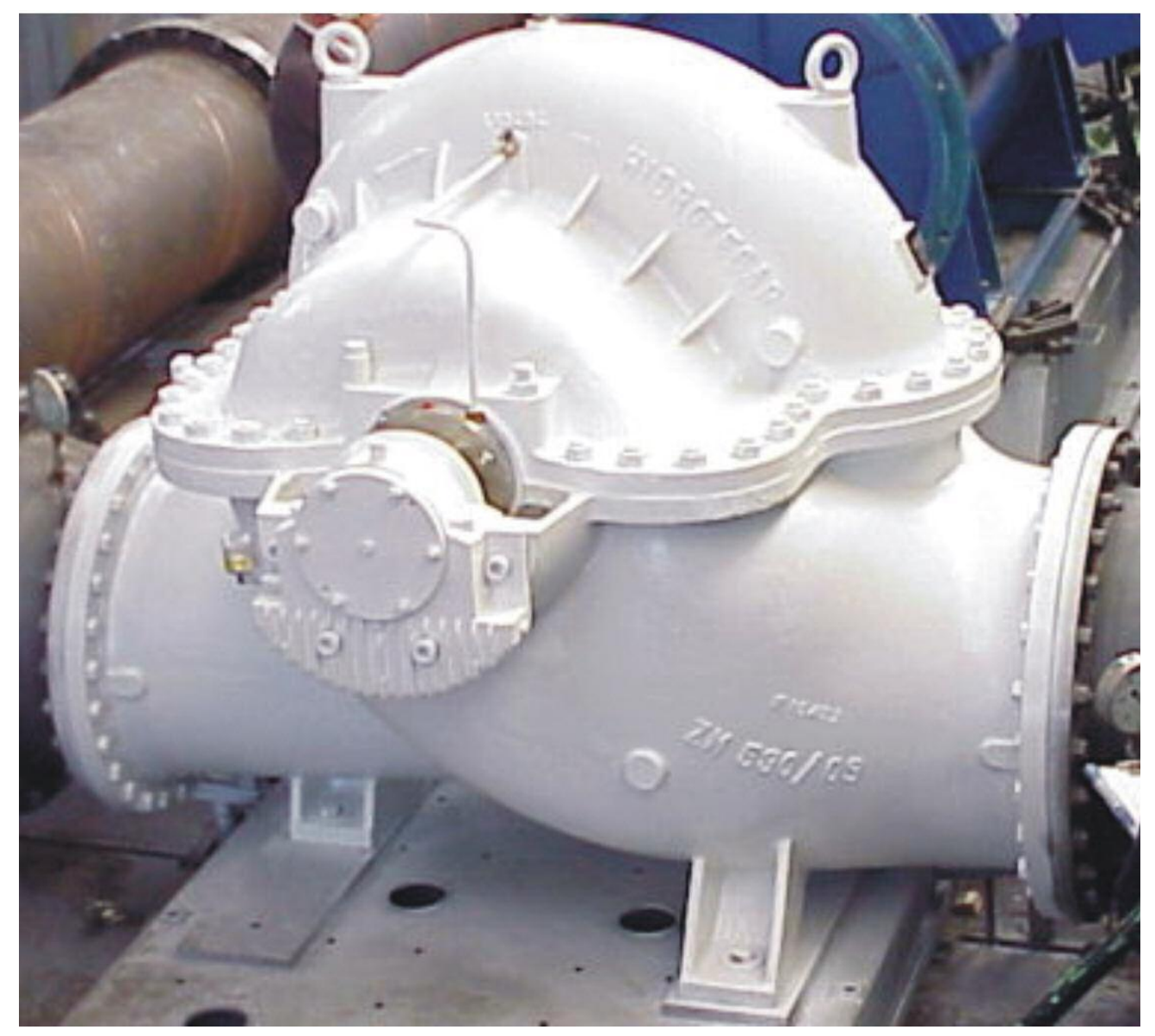

Fig. 1.- Experimental set-up for the pump measurements (dimensions in $\mathbf{m}$ ). 


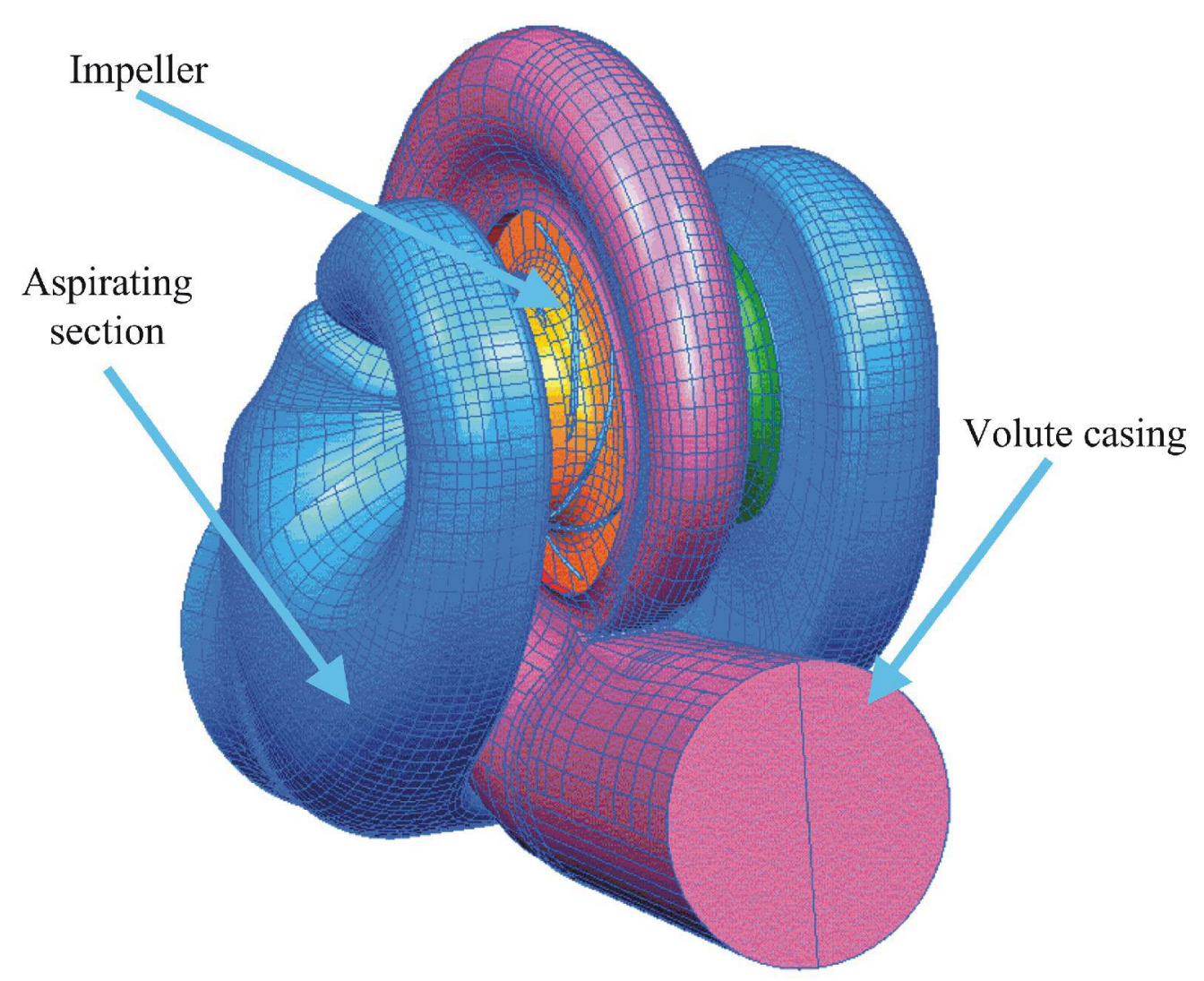

Fig. 2.- Sketch of the pump unstructured mesh. (Inlet and outlet pipe far enough to impose boundary conditions). 


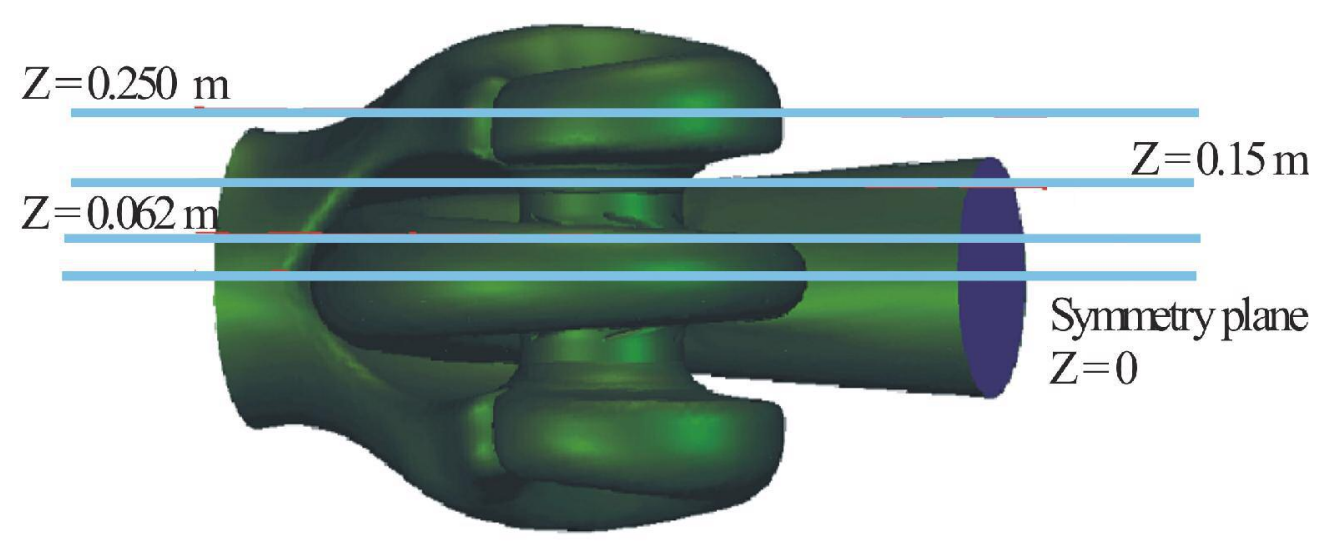

Fig. 3.- Sketch of the pump defining the reference planes.

http://mc.manuscriptcentral.com/fluids 


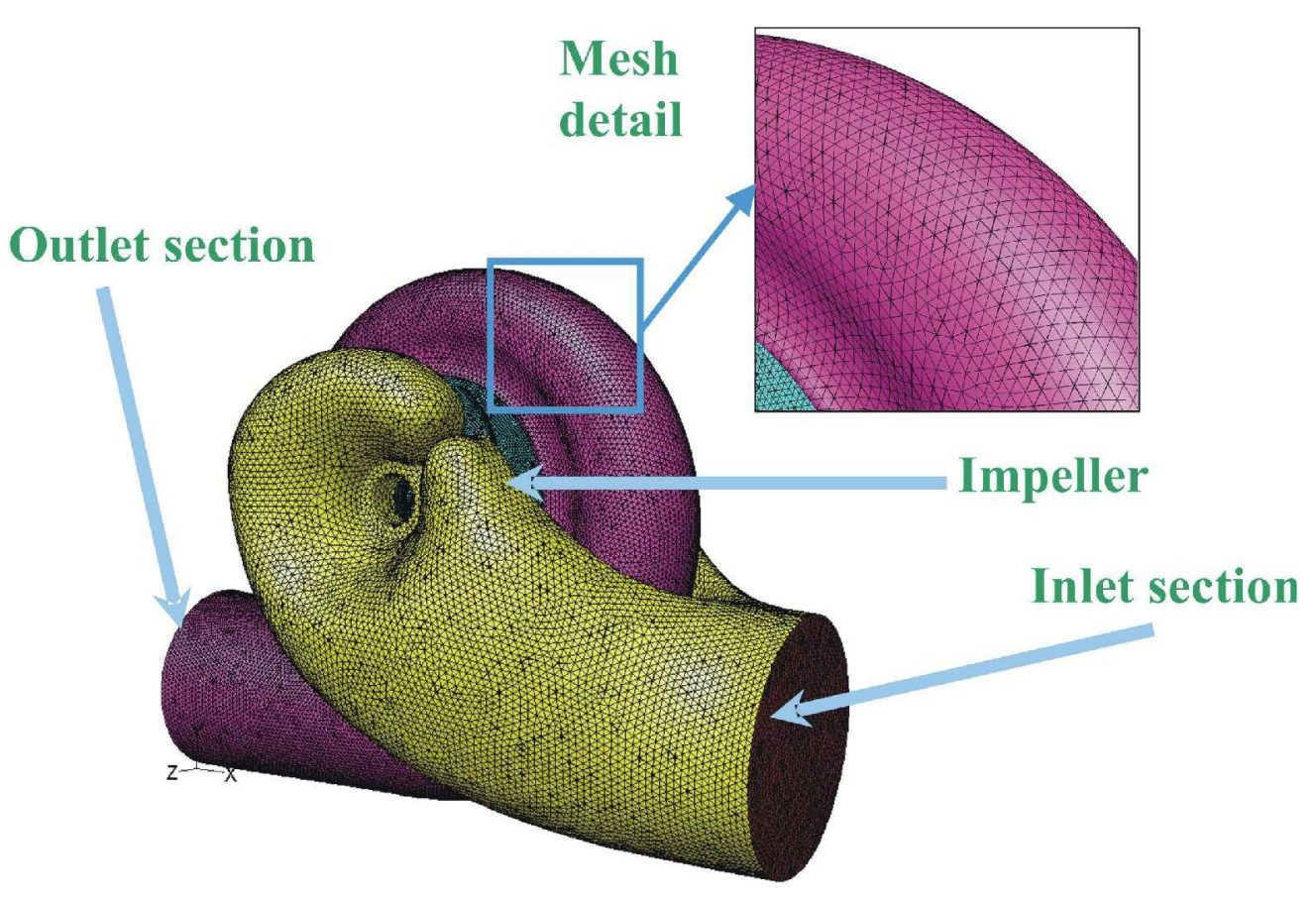

Fig. 4.- Unstructured mesh considered for the numerical study (a detail is enlarged). $184 \times 123 \mathrm{~mm}(300 \times 300 \mathrm{DPI})$ 


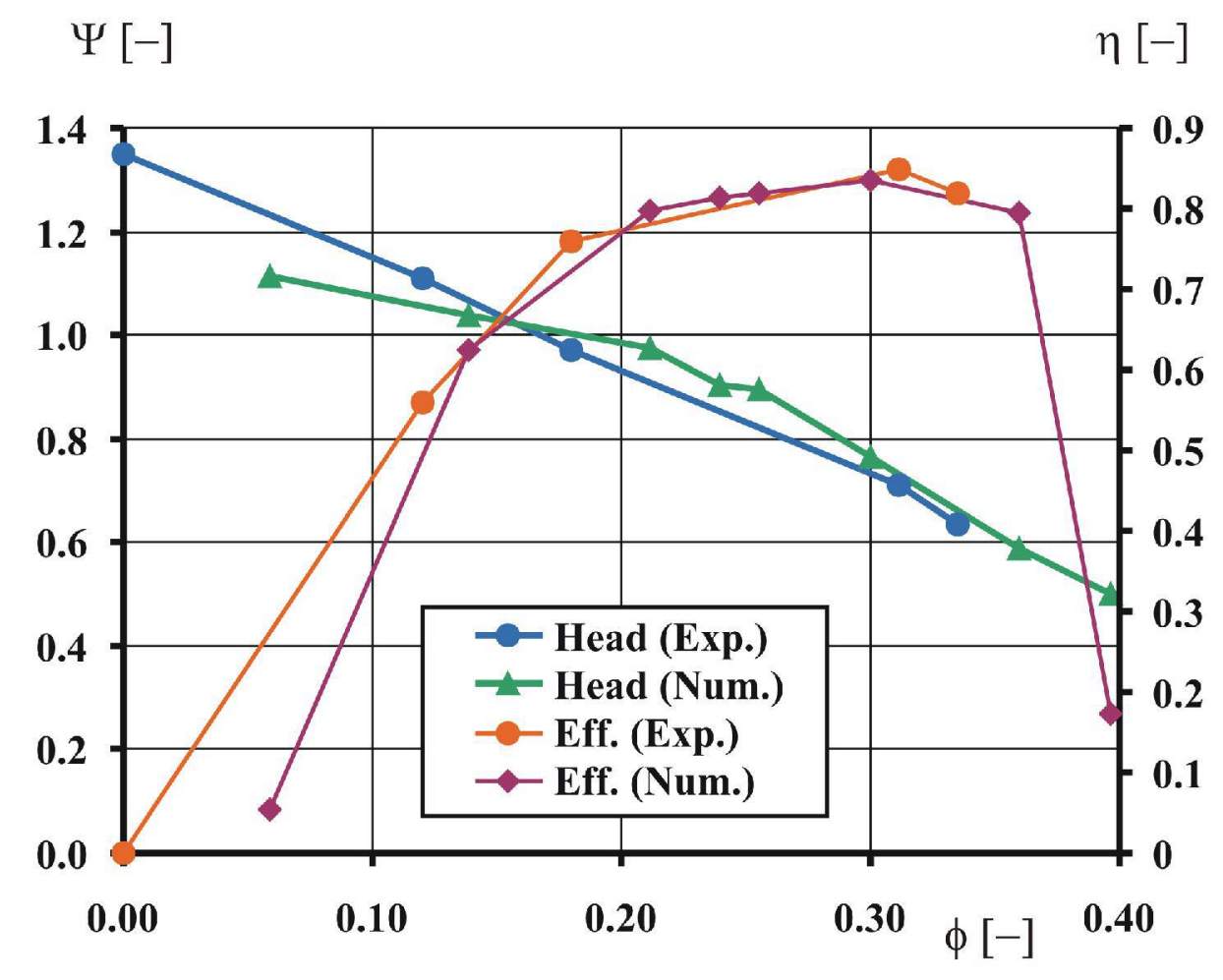

Fig. 5.- Comparison of the performance curves (non-dimensional variables).

http://mc.manuscriptcentral.com/fluids 


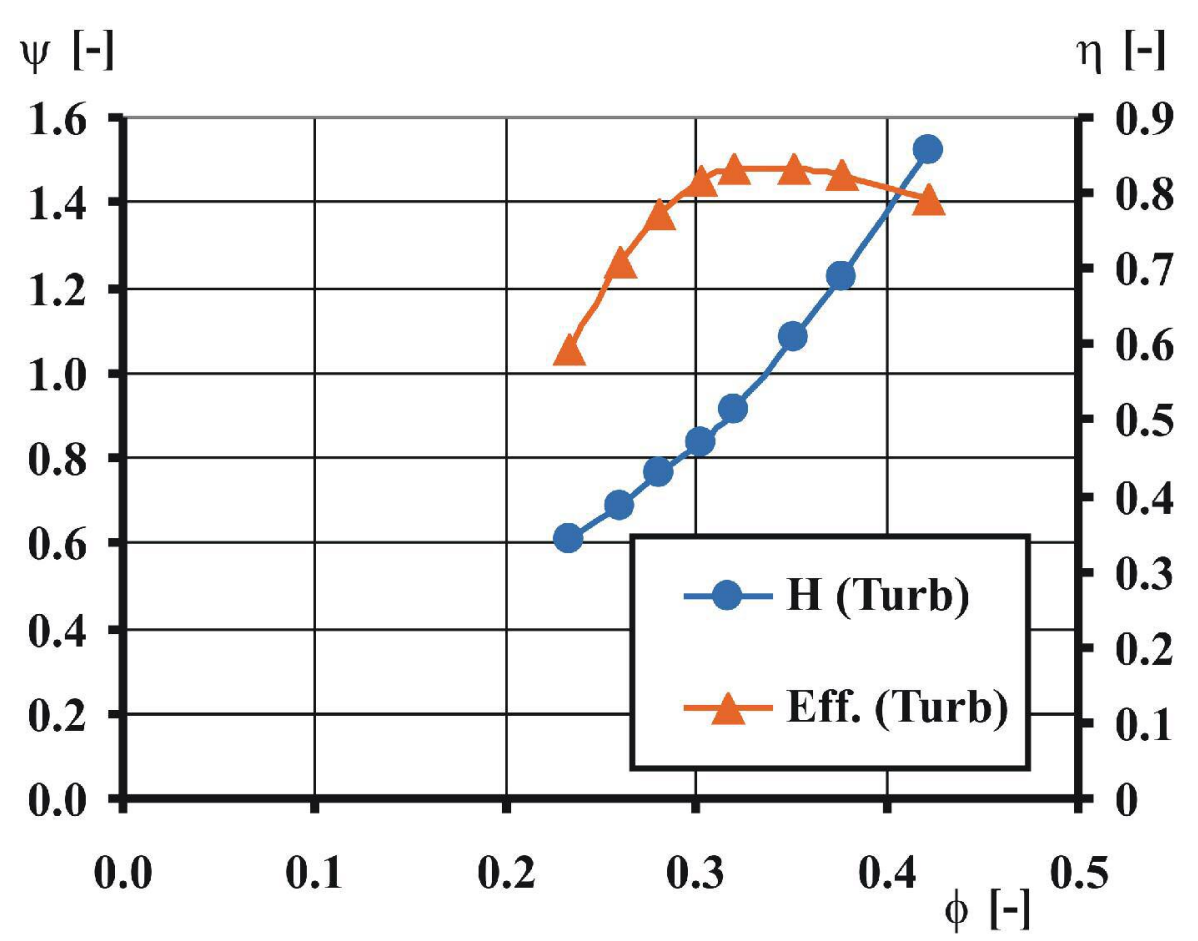

Fig. 6.- Performance curves for the turbine mode of operation (numerical prediction). 

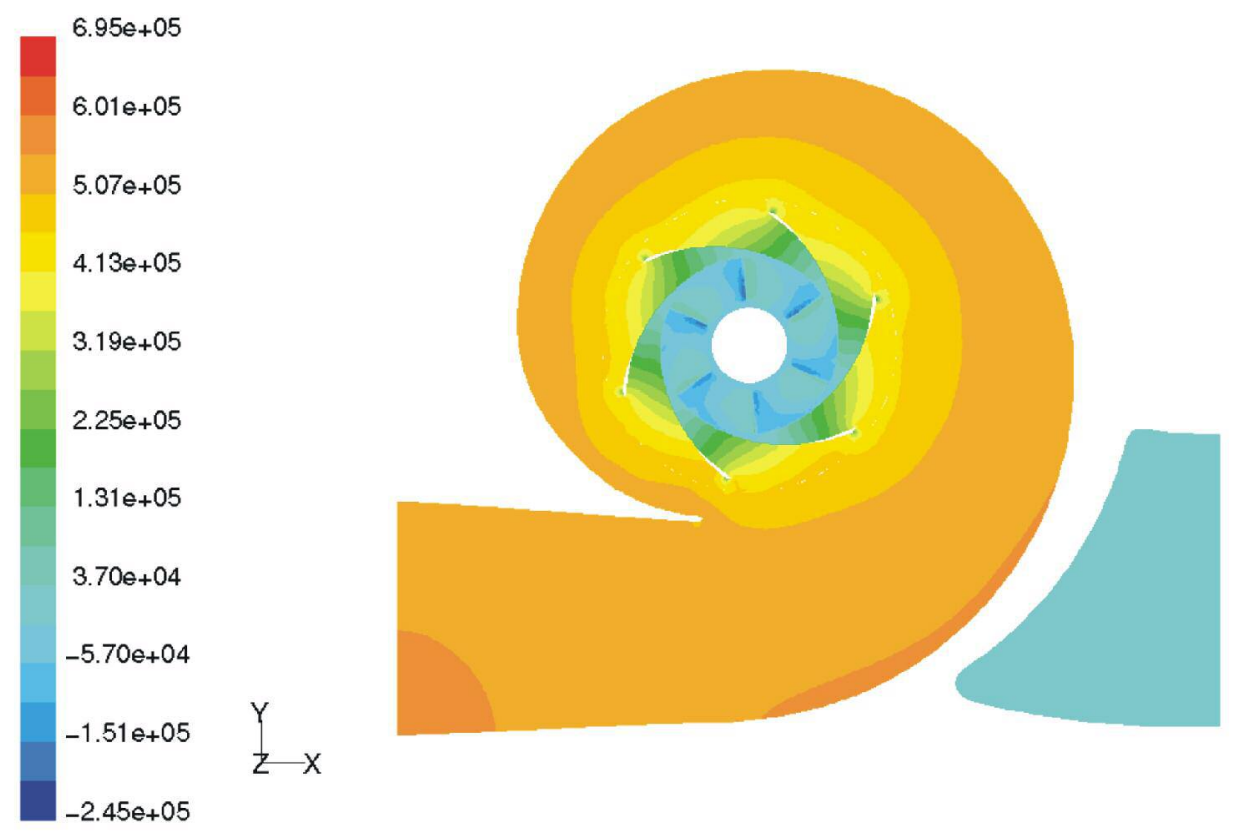

Fig. 7. Static pressure distribution in the $Z=0$ plane for the nominal flow rate $(\phi=$ $0.30)$. 


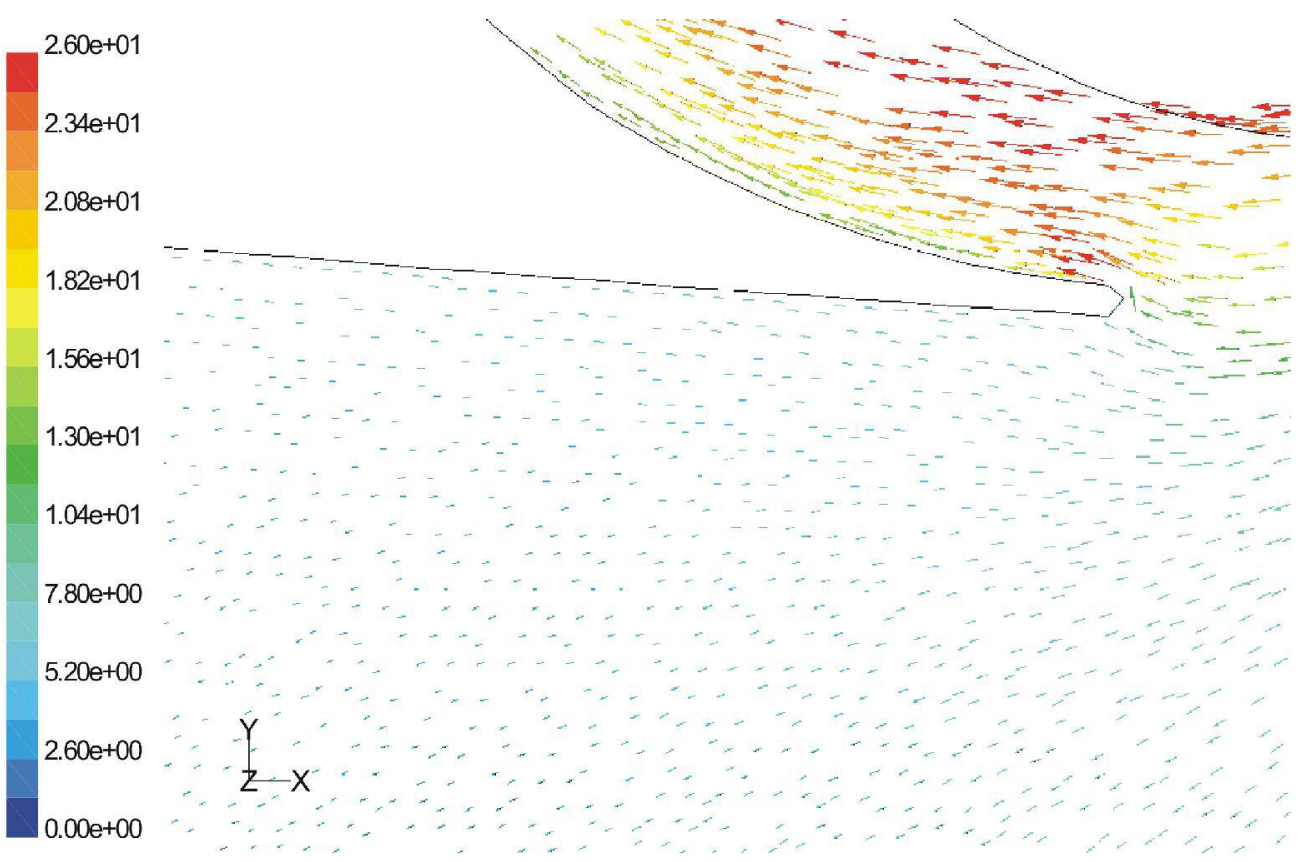

Fig. 8.- Velocity field around the volute tongue for $\phi=0.13$. 


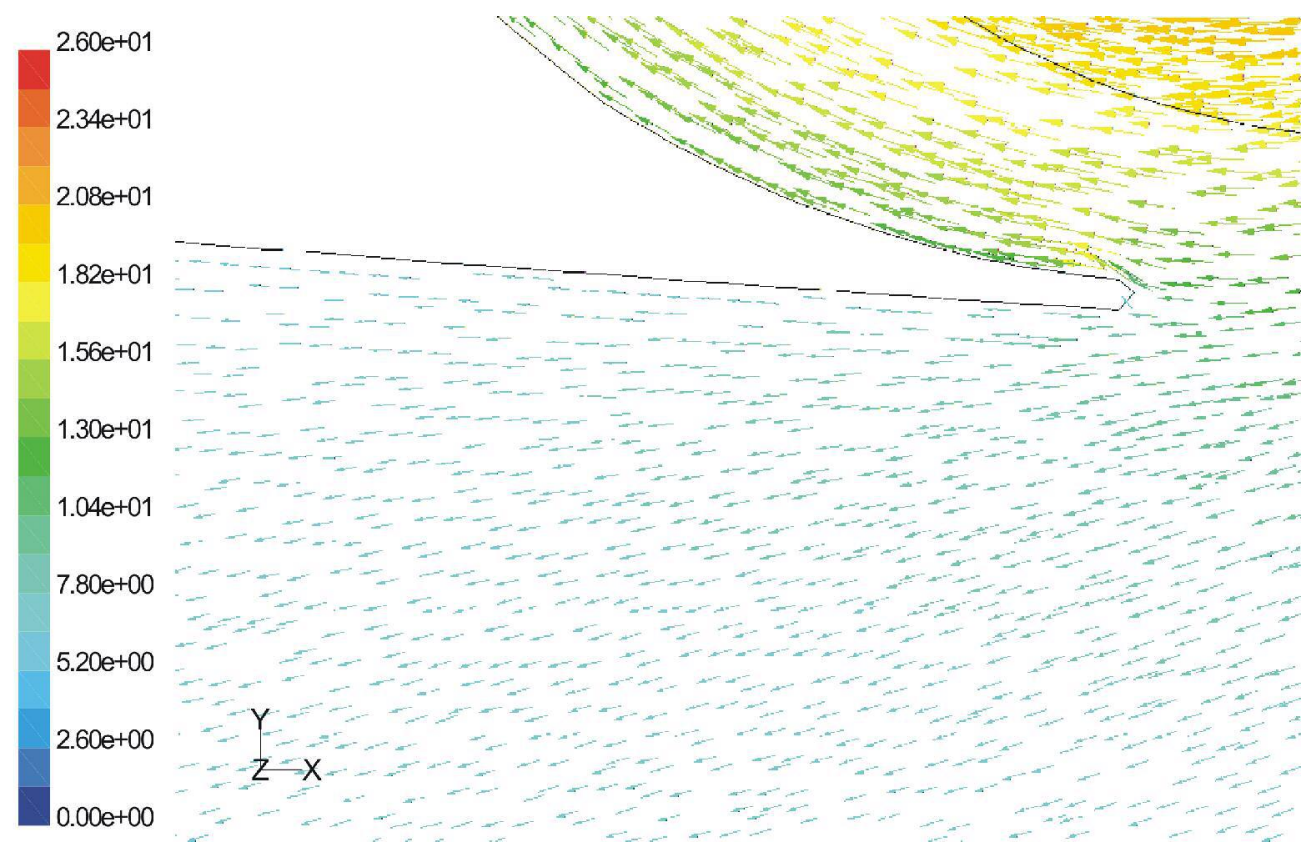

Fig. 9.- Velocity field around the volute tongue for $\phi=0.30$. 


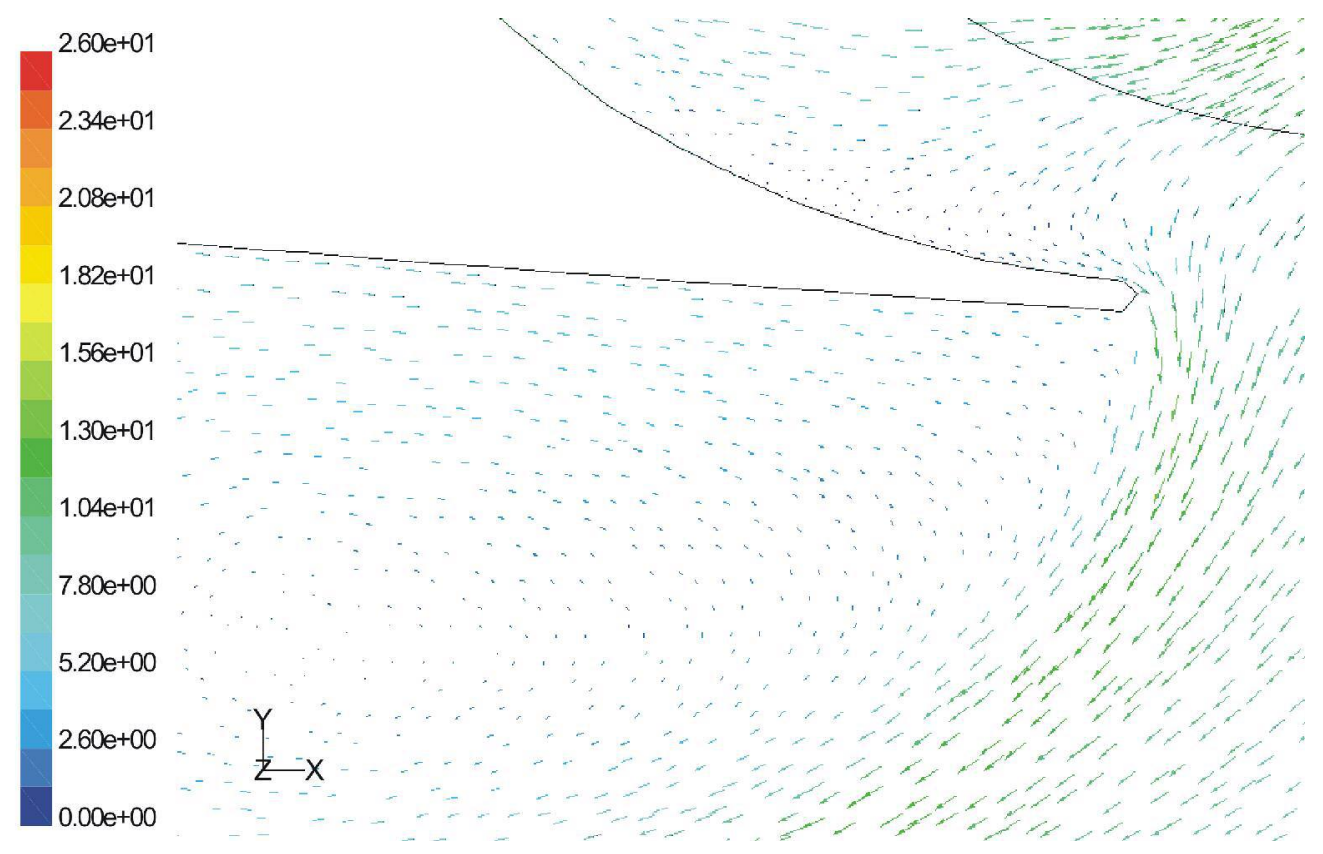

Fig. 10.- Velocity field around the volute tongue for $\phi=0.36$. 


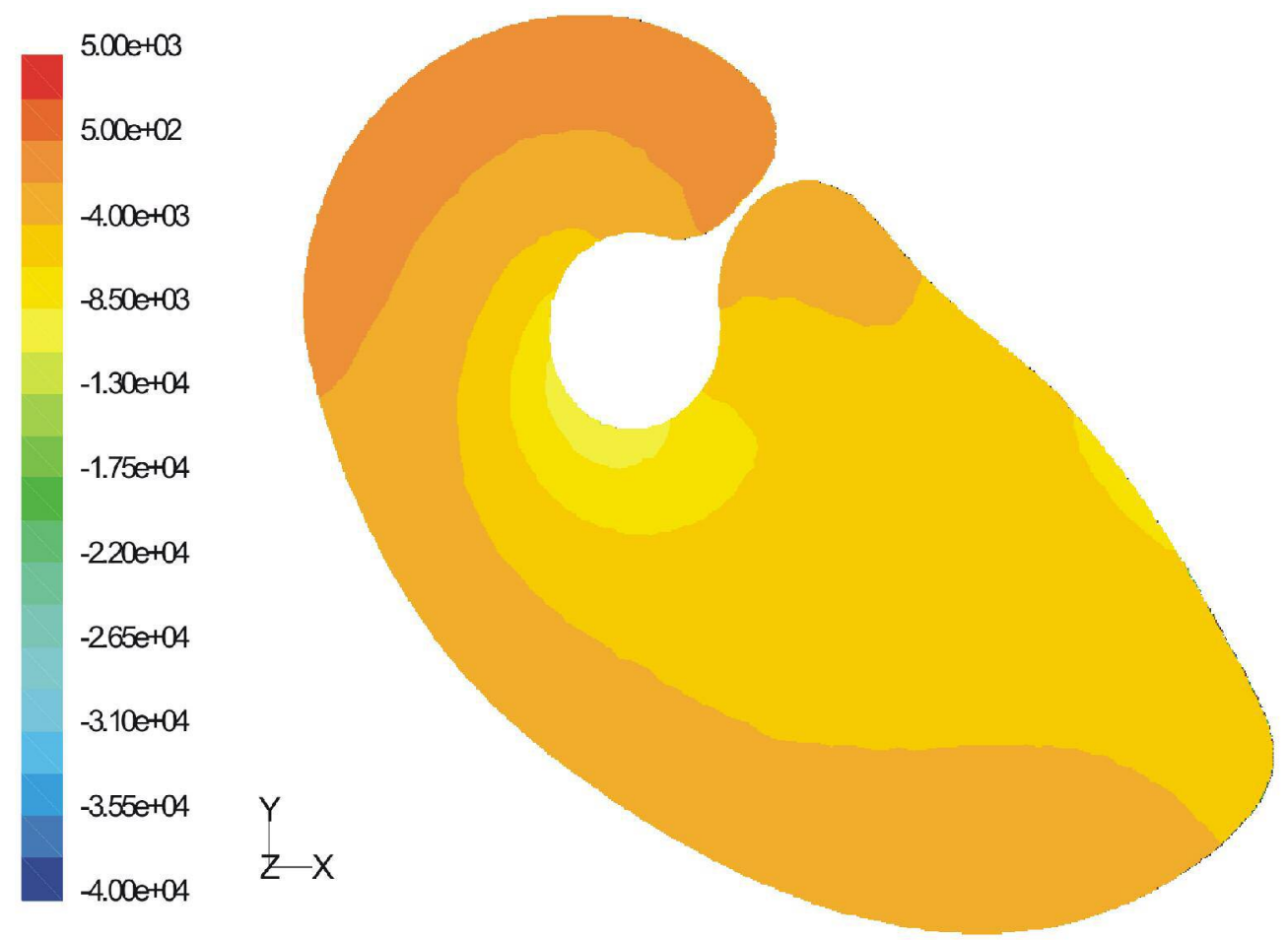

Fig. 11.- Static pressure distribution at the semi-volute suction inlet $(\phi=0.13$ ). 


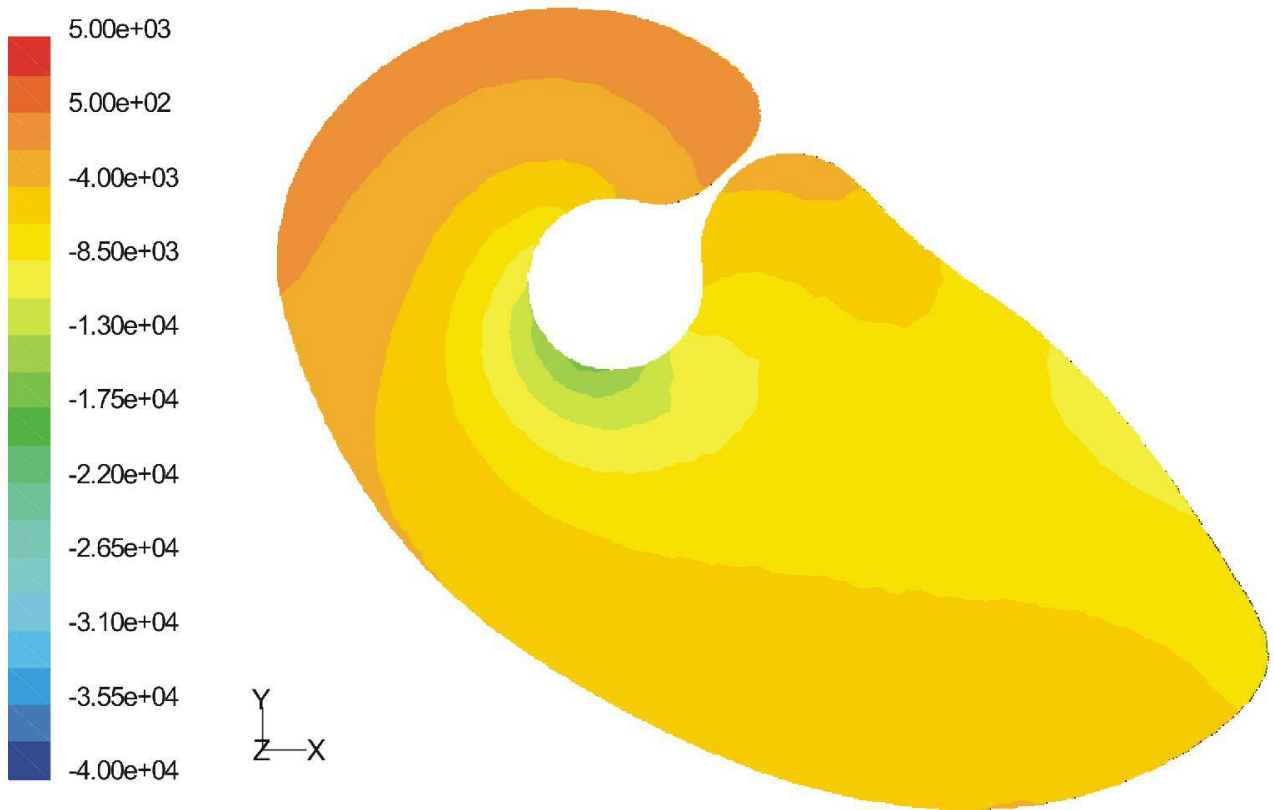

Fig. 12.- Static pressure distribution at the semi-volute suction inlet $(\phi=0.30)$. 


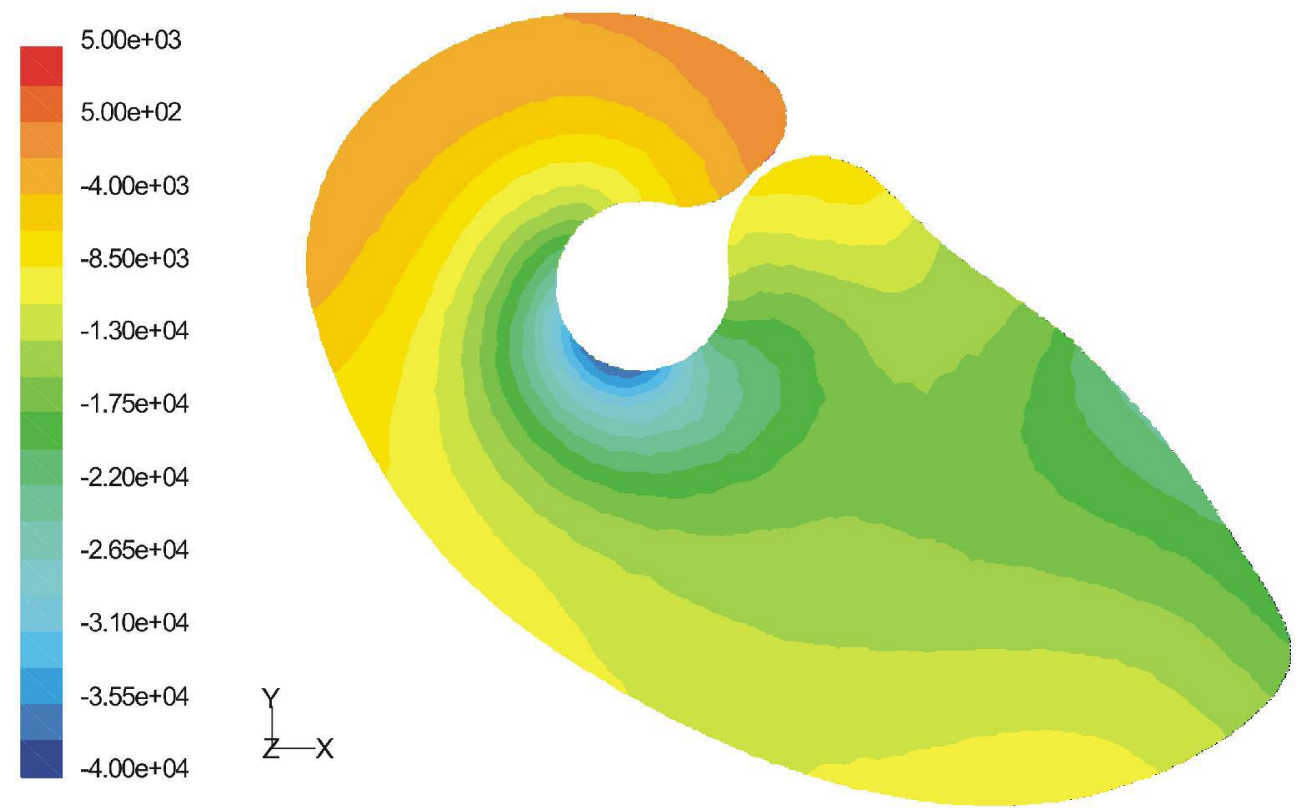

Fig. 13.- Static pressure distribution at the semi-volute suction inlet $(\phi=0.36)$. 


$6.25 e+05$
$5.55 e+05$
$4.84 e+05$
$4.14 e+05$
$3.43 e+05$
$2.73 e+05$
$2.02 e+05$
$1.32 e+05$
$6.10 e+04$
$-9.50 e+03$
$-8.00 e+04$

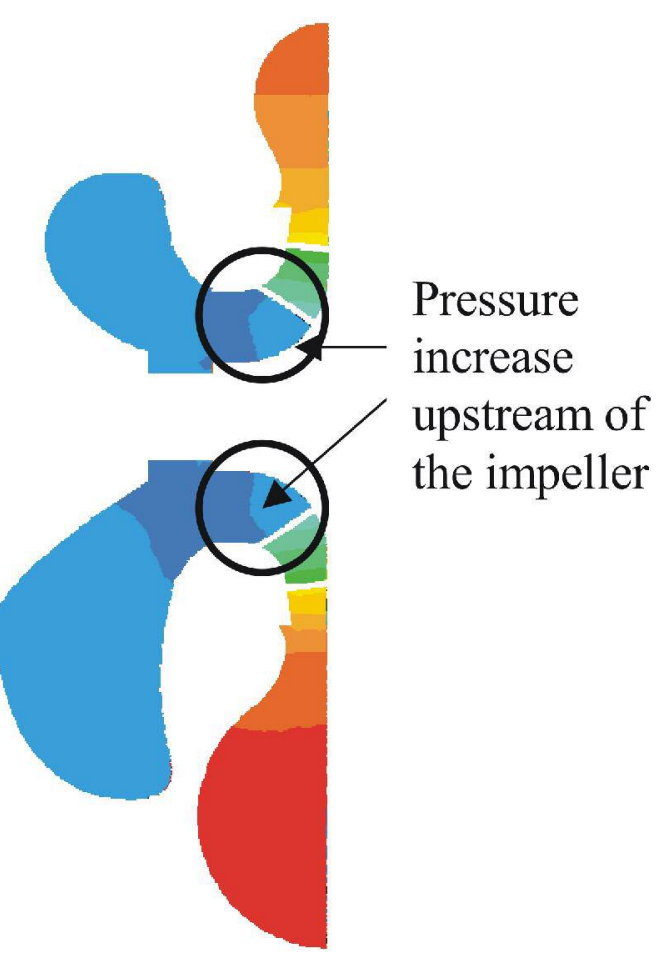

Fig. 14,- Static pressure field at the $X=0$ plane, $\phi=0.13$. 

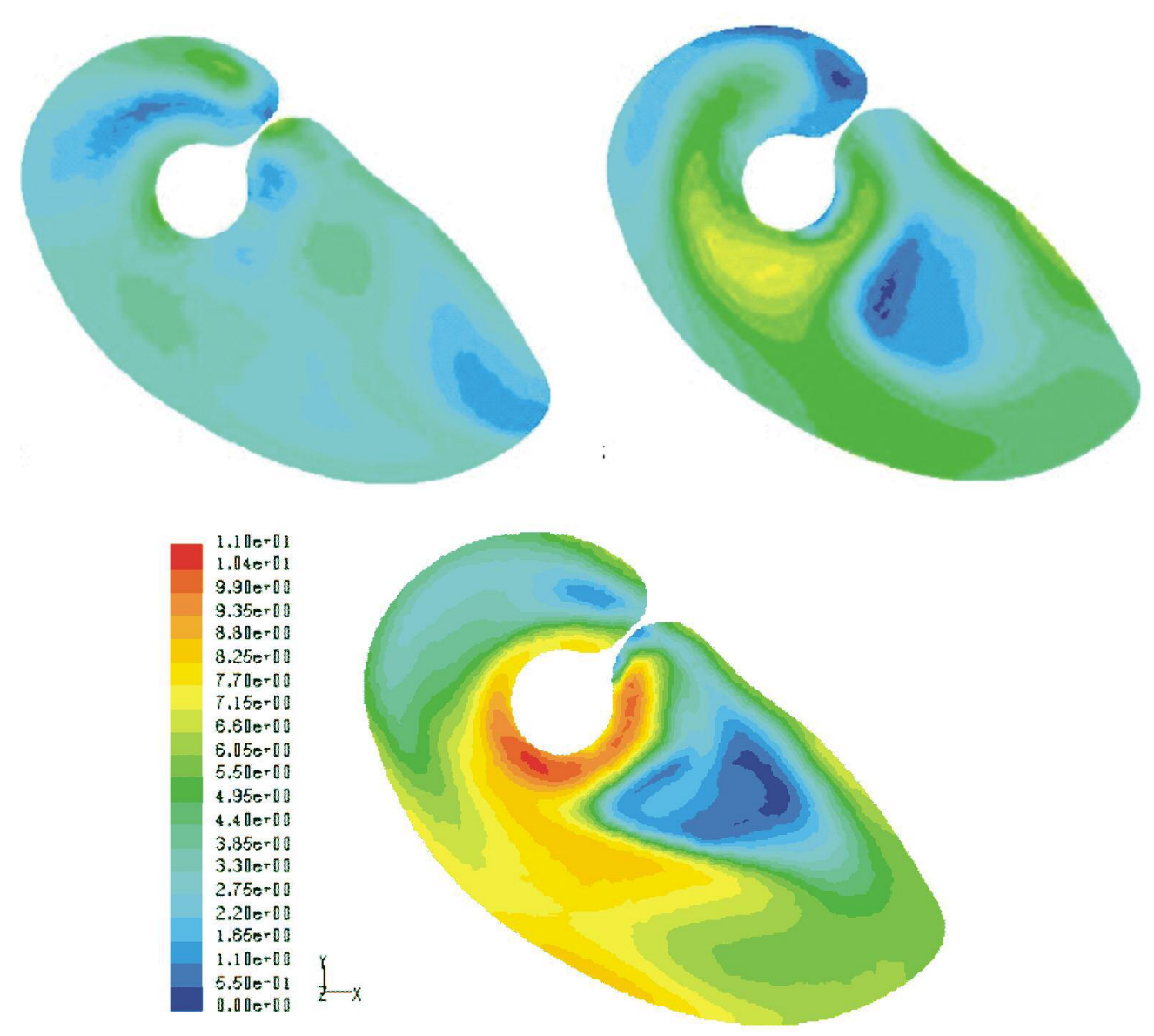

Fig. 15.- Averaged velocity fields at the exit section. Velocity magnitude is plotted for $\phi=$ 0.23 (upper left map), $\phi=0.32$ (upper right map) and $\phi=0.42$ (lower map). 

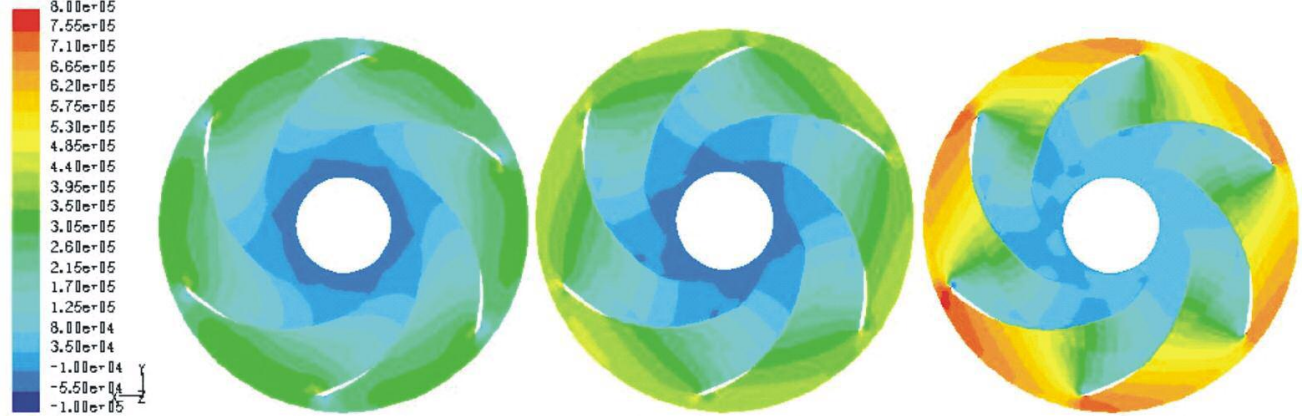

Fig. 16.- Averaged pressure fields in the turbine. $\phi=0.23$ (left hand side), $\phi=0.32$ (centre) and $\phi=0.42$ (right hand side). 
This document is a pre-print version of the scientific paper published by Wiley. It has been released by the authors to fulfill all the publisher requirements established for Article Sharing:

https://authorservices. wiley.com/author-resources/Journal-

Authors/licensing/self-archiving.html

This is the pre-peer reviewed version of the article which has been published in final form at the International Journal of Numerical Methods in Fluids. This version may be used for non-commercial purposes in accordance with Wiley

Terms and Conditions for Use of Self-Archived Versions

\section{(2) $\odot \Theta \Theta$}

(C) 2019. This manuscript version is made available under the Creative Commons Attribution-NonCommercial-NoDerivatives 4.0 International License (CC-BY-NC-ND 4.0 license) http://creativecommons.org/licenses/by-nc-nd/4.0/ 